\title{
A GENERALIZATION OF YOUNG-TYPE INEQUALITIES
}

\section{DAESHIK CHOI}

Abstract. In this paper, we prove a simple but useful result and apply it to give a generalization of Young-type inequalities developed by many researchers. Applications to positive definite matrices will be also provided.

Mathematics subject classification (2010): 15A39, 15A60, 15B48, 47A30.

Keywords and phrases: Young inequality, positive definite matrix, unitarily invariant norm, trace, determinant.

\section{REFERENCES}

[1] D. ChOI, M. KRnIĆ, AND J. PEČARIĆ, Improved Jensen-type inequalities via linear interpolation and applications, J. Math. Inequal. 11 (2017), 301-322.

[2] D. CHOI AND M. SABABHEH, Inequalities related to the arithmetic, geometric, and harmonic means, J. Math. Ineq., vol. 11, no. 1 (2017), 1-16.

[3] M. G. Ghaemi, N. Gharakhanlu, And S. Furuichi, On the reverse Young and Heinz inequalities, J. Math. Inequal. 11 (2017), 641-652.

[4] C. HE AND L. Zou, Some inequalities involving unitarily invariant norms, Math. Inequal. Appl. 12 (4) (2012) 767-776.

[5] O. Hirzallah And F. KitTaneh, Matrix Young inequalities for the Hilbert-Schmidt norm, Linear Algebra Appl. 308 (2000) 77-84.

[6] F. Kittaneh And Y. ManasRah, Improved Young and Heinz inequalities for matrices, J. Math. Anal. Appl. 361 (2010), pp. 262-269.

[7] F. Kittaneh and Y. ManasRah, Reverse Young and Heinz inequalities for matrices, Linear Multilinear Algebra. 59 (2011), pp. 1031-1037.

[8] Y. Manasrah And F. Kittaneh, A generalization of two refined Young inequalities, Positivity (2015) 19: 757-768. 